\title{
Anomaly in the earth magnetic field at north provinces of Najaf city
}

\author{
Arif S. Baron \\ Department of Physics, College of Science, University of Al-Kufa \\ E-mail: Arif.aljuburi@uokufa.edu.iq
}

\begin{abstract}
This paper investigated in the numerical simulation model to calculate the Earth magnetic field components at north provinces of Najaf city (Longitude $44.316^{\circ}-44.3592^{\circ} \mathrm{E}$ and Latitude $32.0508^{\circ}$ $32.0256^{\circ} \mathrm{N}$ ). The components of the Earth magnetic field (total intensity (F), horizontal intensity (H), declination (D), inclination (I), the north component $(\mathrm{X})$, the east component(Y), and Down component(Z)) were found by using spherical harmonic world magnetic model (WMM2010). A great deal of anomaly has been discovered in all components of the Earth magnetic field at the selected region (Long. $44.345^{\circ}-44.335^{\circ}$ E, Lat.32.042 $-32.032^{\circ} \mathrm{N}$ ) using Kriging method. This anomaly can be attributed either to oil rich region or cracking in the Earth crust.
\end{abstract}

Key words

WMM2010, Geomagnetic field anomaly, Contour map.

\section{Article info.}

Received: Jun. 2013

Accepted: Jan. 2014

Published: Apr. 2014

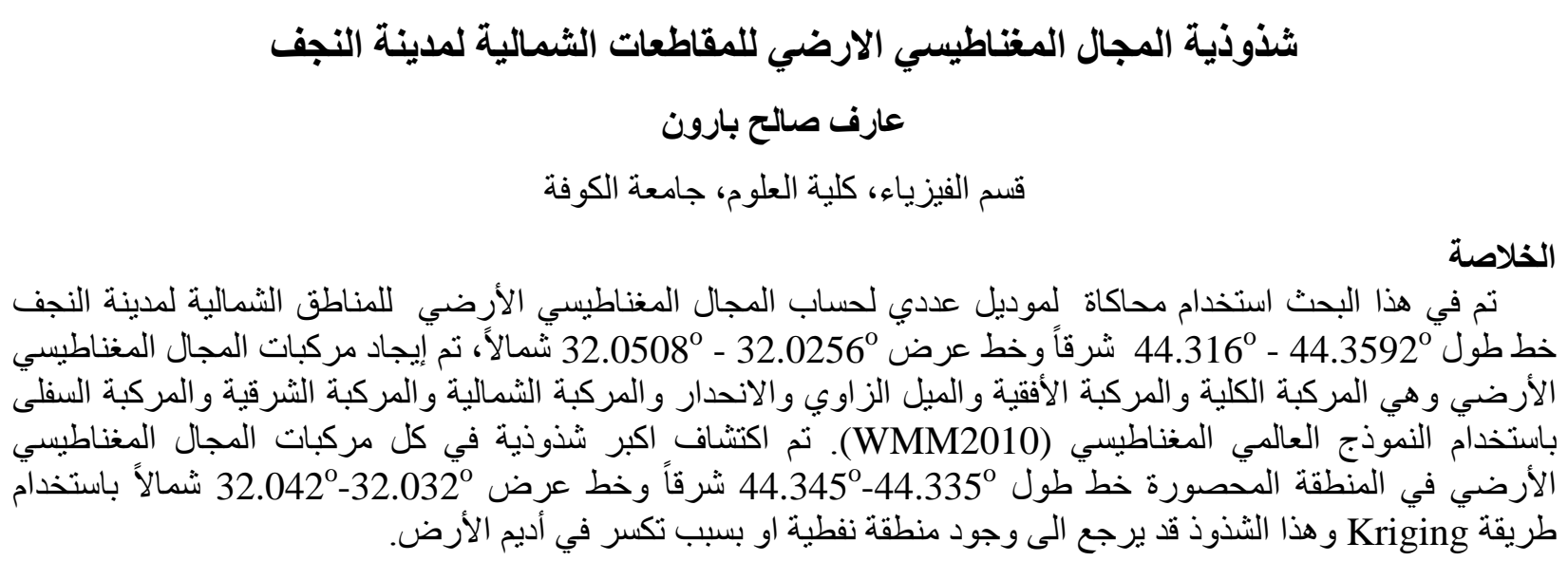

\section{Introduction}

The World Magnetic Model (WMM) is a standard model of the core and large-scale crustal magnetic field. The WMM is used as a standard model, for the US Department of Defense, the UK Ministry of Defense, the North Atlantic Treaty Organization (NATO), and the World Hydrographic office (WHO). It is widespread, in the meantime, also in the civil navigation. The model, the accompanying software and documentation are administered by the
United States National Geophysical Data Center (NGDC) and the Us National Geospatial-Intelligence Agency (NGA). produced by in cooperation with the British Geological Survey (BGS). The model aims to provide a trusty estimate of the magnetic field's strength and direction on or near the Earth's surface. It is also predicts the change in the field over the next five years. The gravity and aeromagnetic anomalies of a local area in northern central Turkey 
obtained from the General Directorate of Mineral Research and Exploration of Turkey (MTA) used to estimate the heading to estimate In this paper the region of interest was divided into grid points with equal distances between two adjacent points (11 line of longitude and 8 lines of latitude).The results were obtained in the form of contour map for each component of the Earth magnetic field.

\section{Theoretical model}

The World Magnetic Model (WMM) was implemented in the survey. This model can be applied for magnetic survey in air, sea navigation systems and ground. The WMM is a model of the Earth's main source body magnetization investigated by Bilim and Ates in 2004[1]. The magnetic field data on 74 survey sites during 2001-2007, which was measured in the Philippines by DI Chuan-Zhi and groups [2]. Angelo De Santes et. al. calculated the Earth magnetic elements by using a new model( ITGRF) and compare this model with IGRF model to the Italian observatory (CastelloTesino) [3]. In 2010 Enkelejda Q. et. al. measured the magnetic taken during different the campaigns in Albania and Italy in time of concern, together with a total intensity data set from the Ørsted and CHAMP satellite missions [4]. A polynomial model of magnetic declination for the area of Slovenia is presented by T. Zagar and D. Radovan and compared this model with the World Magnetic Model (WMM) [5]. The magnetic anomaly in the sea of Najaf was found by Mohammad J. et. al. by using IGRF2010 in 2013[6], investigations, which needs more. It also used widely civilian navigation and in the systems magnetic field, that portion of the field generated in the Earth's core. The magnetic field is modeled as the negative gradient of a scalar potential $\mathrm{V}$ which can be represented by a truncated series expansion[7,8]:

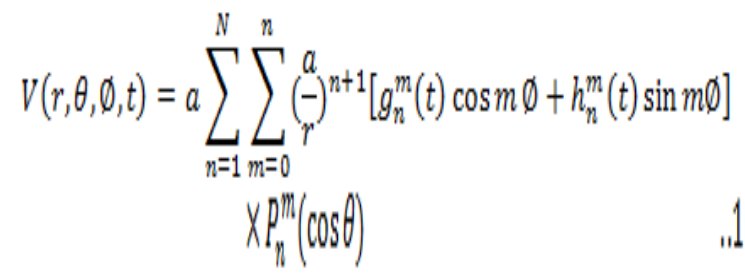

where $\mathrm{a}=6371.2 \mathrm{~km}$ is a reference radius, $(r, \theta, \emptyset)$ are geographic coordinates where $r$ is the distance from the center of the Earth in $\mathrm{Km}, \theta$ denotes the co-latitude while $\emptyset$ denotes the longitude, $P_{n}^{m}$ are the Schmidt quasi-normalized associated Legendre functions of degree $n$ and order $m$, the coefficients $g_{n}^{m}$ and $h_{n}^{m}$ are the Gauss coefficients at time, and $N$ is the maximum degree and order of the internal expansion, which is taken here to $N=50[9,10]$.

$\dot{X}=\sum_{n=1}^{N}\left(\frac{a}{r}\right)^{n+2} \sum_{m=0}^{n}\left[\dot{g}_{n}^{m}(t) \cos m \emptyset+\dot{h}_{n}^{m}(t) \sin m \emptyset\right] \frac{\partial p_{n}^{m}(\cos \theta)}{\partial \theta}$
$\dot{Y}=\sum_{n=1}^{N}\left(\frac{a}{r}\right)^{n+2} \sum_{m=0}^{n} m\left[\dot{g}_{n}^{m}(t) \cos m \emptyset+\dot{h}_{n}^{m}(t) \sin m \emptyset\right] p_{n}^{m}(\cos \theta)$
$\dot{Z}=-\sum_{n=1}^{N}(n+1)\left(\frac{a}{-}\right)^{n+2} \sum_{m=0}^{n} m\left[\dot{g}_{n}^{m}(t) \cos m \emptyset+\dot{h}_{n}^{m}(t) \sin m \emptyset\right] p_{n}^{m}(\cos \theta) . .4$ The first derivative $\dot{g}_{n}^{m}(t)$ and $\dot{h}_{n}^{m}(t)$ will be given by the satellite model POMME-4.2S $[11,12]$.

\section{Results and Discussion}

Simulation of WMM2010 was used to verify the geomagnetic field components $(\mathrm{Z}, \mathrm{Y}, \mathrm{X}$, H, I, D and F) for selected area at the North's part of Najaf city called North quarters region. The coordinates are (long. $44.345^{\circ}$ $44.335^{\circ} \mathrm{E}$, lat. $32.042^{\circ}-32.032^{\circ} \mathrm{N}$, altitude $=38-51 \mathrm{~m}$ above mean sea level). Where the inputs to the model are longitude, latitude (degree) and altitude in meters with respect to mean sea level and the local time of Najaf city. The results were explained as contour map for each component as shown in the following figures. Fig.1 shows the Down component $(\mathrm{Z})$ of the geomagnetic 
field. It can be seen from this figure that two regions appears a sharp deviation first region consist of two lines of isomagnetic field of values (34590 and 34600nT) and there are two lines (34550 and 34560nT) formed another region. This regions represent anomaly behavior in the counter map limit in the area (long. $44.342^{\circ}$ $44.333^{\circ}$ East, lat.32.042 $-32.025^{\circ}$ North).

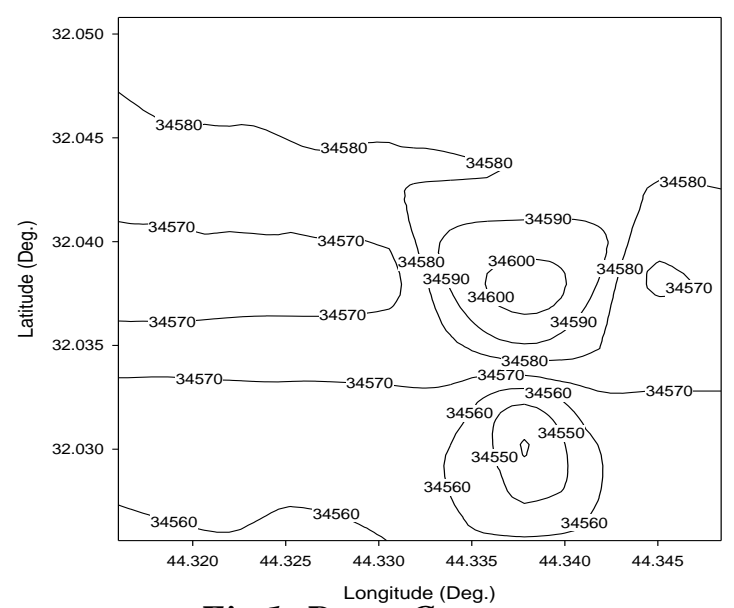

Fig. 1: Dawn Component.

Another anomaly appears clearly in the Fig.2 for East component (Y) at the same area. There are two lines of force (for the first region 2142 and 2141.5 nT) and three lines (for the second region 2140, 2139.5 and 2139nT) these lines cuts at longitude $44.342^{\circ}$ $44.333^{\circ} \mathrm{E}$, latitude $32.042^{\circ}-32.025^{\circ} \mathrm{N}$ and 44-41 $\mathrm{m}$ above mean sea level.

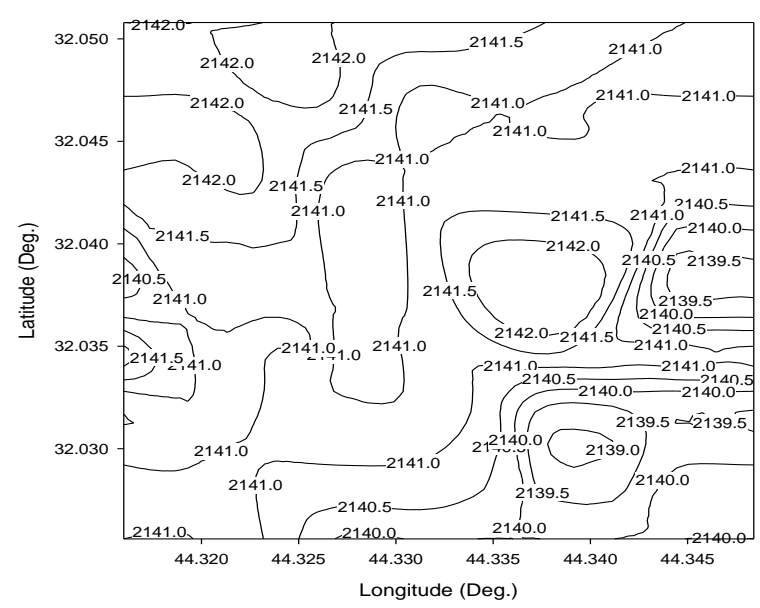

Fig.2: East Component.
Fig.3 explain the North component (X)where the anomaly happened in the same area (long. $44.342^{\circ}-44.333^{\circ}$ E, lat. $32.042^{\circ}-32.025^{\circ} \mathrm{N}$ ) at the values (29830 and $29825 \mathrm{nT}$ ) for first region and (29850 and $29845 \mathrm{nT}$ ) for second region, while the anomaly in the Horizontal component $(\mathrm{H})$ appear in the Fig. 4 in too two regions at the values $(29905,29900 \mathrm{nT})$ and $(29930$, 29925 and $29920 \mathrm{nT}$ ) certain in the same area. Inclination (I) and Declination (D) show in the Figs. (5 and 6) respectively at which the anomaly seem clearly in the Inclination at the values are $(49.17,49.16,49.17$ deg.) and (49.11, 49.10, 49.09 deg.) while that appear in the Declination at the values (4.100, 4.098 and 4.108, 4.106 deg.). Finally the total component of magnetic field (total intensity F) appear in the Fig.7 and exactly in the same region (Long. $44.342^{\circ}-44.333^{\circ} \quad$ E, Lat.32.042 ${ }^{\circ}$ $\left.32.025^{\circ} \mathrm{N}\right)$ at the values $(45725 \mathrm{nT})$ for first region and (45710 and $45705 \mathrm{nT}$ ) for second region. This anomaly in all Earth magnetic elements can be as cribbed to the oil-rich area or cracking in the layers of the Earth in this region.

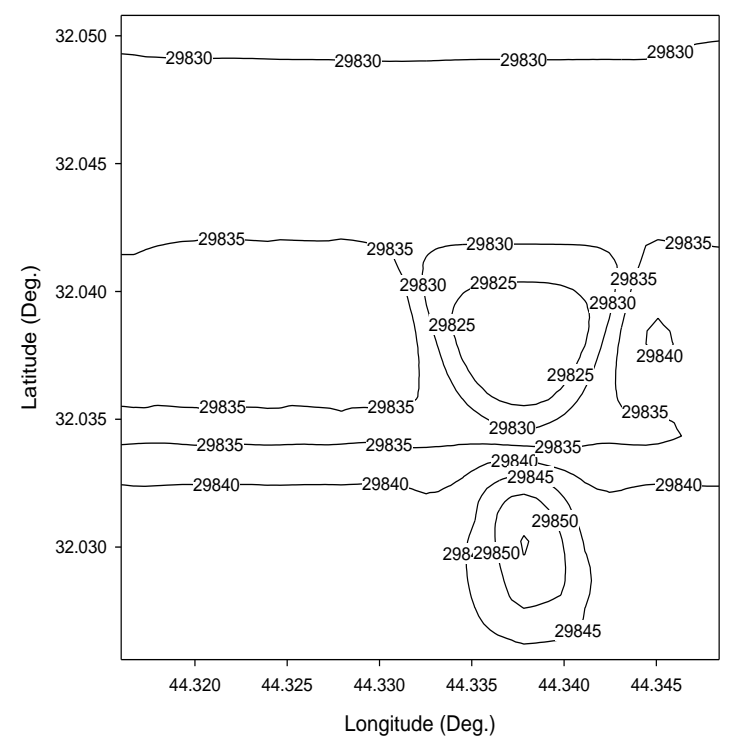

Fig.3: North Component. 


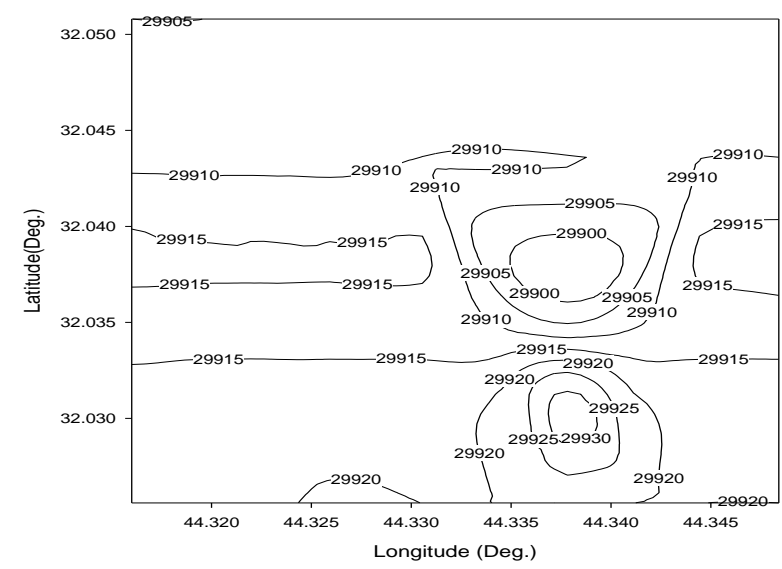

Fig.4: Horizontal component

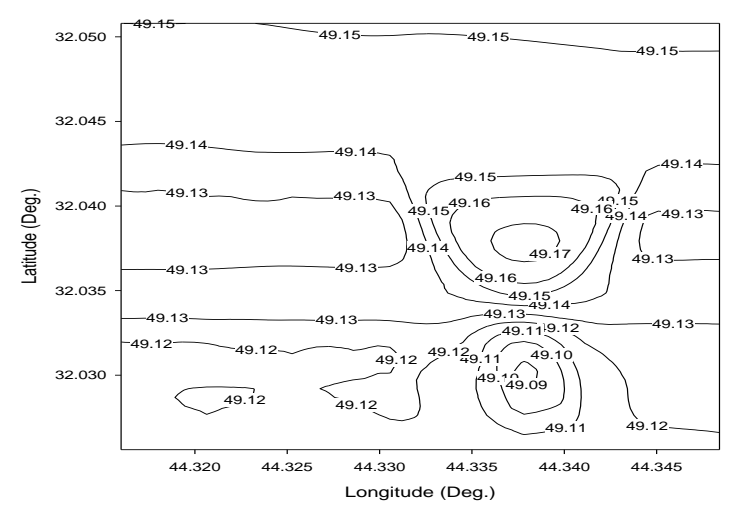

Fig.5: Inclination component.

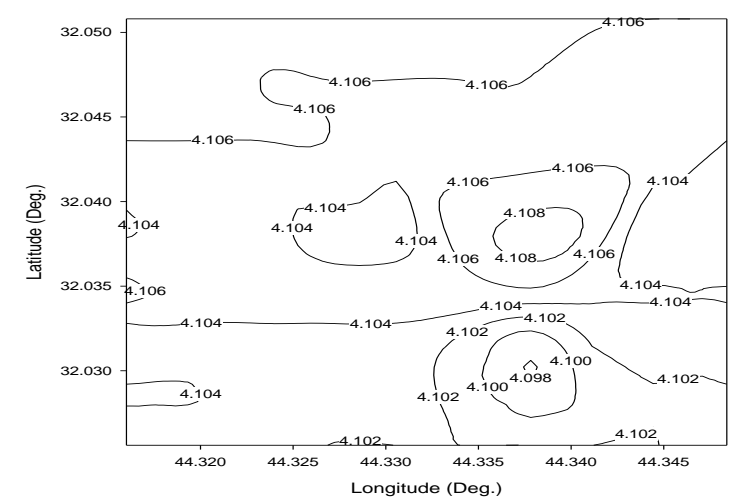

Fig.6: Declination component.

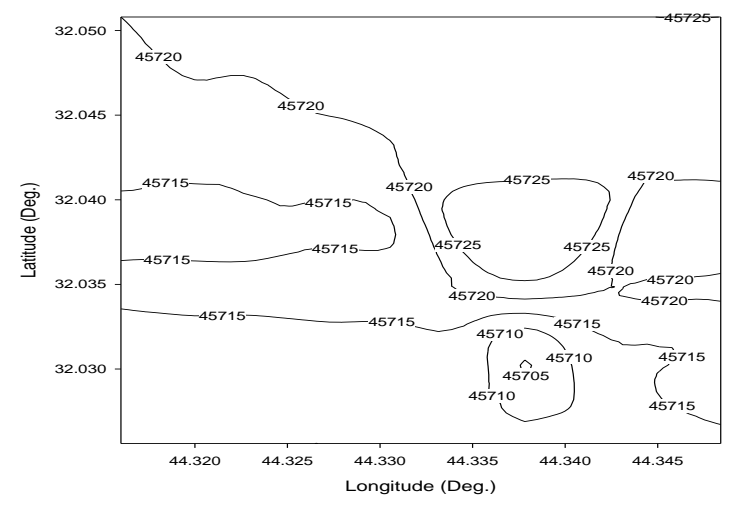

Fig.7: Total component. 


\section{Conclusions}

The magnetic anomaly at North quarters region in the north of Najaf city was investigated using WMM2010 model. The magnetic anomaly was found by using contour map for Earth magnetic field at this region exist in this area long. $44.342^{\circ}-44.333^{\circ} \mathrm{E}$, Lat. $32.042^{\circ}-32.025^{\circ} \mathrm{N}$. These anomalies may be attributed to the existence of cracking in the Earth crust or oil rich region. However, this area needs more investigations experimentally and theoretically.

\section{References}

[1] F. Bilimand A. Ates, J. of Balkan Geo. Soc., 7, 2 August (2004) 12-22.

[2] D.Chuan-Zhi, GU Zuo-Wen, B. M. Soriano, C. Bin Carina G. Lao, Zhang Yi, XIN Chang-J. and GAO Jin-T., Ch. J. of Geo., 54, 4( 2011) 508-515.

[3] S. Angelo De., Luis G., Guido D., Antonio M.,J. Miquel and R. Tozzi, Annals of Geophysics, 46, 3June (2003) 491-500.

[4] Q. Enkelejda, D. Angelo, C. Gianfranco, D. Bejo, R.Luis, D.Guido, and $\mathrm{H}$ Niko., Earth Planets Space, 62(2010)833-841.

[5] T.Zagar and D. Radovan, Geod. Ves., 56, 2 (2012)267-274.
[6] J. Mohammad Al-Bermani, J. Nasser Al-Obeidi and Amer Atyah Laftah, App. Sci., 2,6 (2013)10-18.

[7] F. Mohammad Nizam, Renuganth Varatharajoo, Journal Mekanikal, 23June (2007) 31-39.

[8]B.Langlais and M.Mandea, Earth Planets Space, 52 (2000) 1137-1148.

[9]V.Lesur, Susan M., and T.Alan, E. P. S., 57 (2005) 1157-1163.

[10] C. C. Finlay, S. Maus, C. Beggan, T.Bondar, A.Chambodut, T.Chernova, A.Chulliat, V. Golovkov, B.Hamilton, M. Hamoudi, R. Holme, G.Hulot, W.Kuang, B. Langlais, V.Lesur, F.Lowes, H.L"uhr, S.Macmillan, M. Mandea, S.McLean, C.ManojM. Menvielle, I.Michaelis, N. Olsen, J. Rauberg, M. Rother, T. Sabaka, A. Tangborn, L. Tøffner, E. ebault, A. Thomson, I.Wardinski, Z. Wei1 and T. Zvereva, Geo. J. Int., 183 (2010) 1216-1230.

[11] G.Zuowen, Z.Zhijia, G.Jintian, H.Wei, A. Zhenchang, Y. Tongqi, and C.Bin, E. P. S., 58 (2006)741-750.

[12] G. Jin-Tian, A. Zhen-Chang, G.Zuo-Wen, W.Han, Z.Zhan, T. Yao, Ch. J. of Geo., 48, 1( 2005) 66-73. 